\title{
Feasibility and safety of whole-body vibration therapy in intensive care patients
}

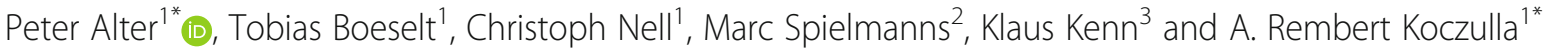 \\ See related research by Wollersheim et al. http://ccforum.biomedcentral.com/articles/10.1186/s13054-016-1576-y
}

We read with great interest the article by Wollersheim and colleagues who examined whole-body vibration (WBV) in intensive care unit patients [1]. Hemodynamic characteristics were monitored during WBV application. The study underscores previous findings showing that no significant changes in heart rate, blood pressure, or oxygen saturation occurred during WBV in critically ill patients, nor when compared with healthy controls [2].

In the present study, unconscious sedated patients received WBV in a flat supine position without any changes in body position, except flexion of the hips and knees. The method raises the question whether enough load was applied to the vibrating plate to lead to a sufficient neuromuscular response. To increase this load and involve neuromuscular recruiting, it might be helpful to modify the patient's position by inclination of the bed to approximately $20^{\circ}$ to $25^{\circ}$ degrees of tilt [2]. It is suggested that this would involve a greater muscular proportion of the whole body. In conscious patients, additional training effects may be achieved by the use of a (yet customized) vibrating dumbbell for the upper extremities.

Since the recent method is preliminary in the current setting, potential effects on muscle function and morphology should be assessed in further studies [3]. A short-term response could be detected, e.g., by electromyography [2]. Longer-term effects involve muscular morphology, e.g., hypertrophy, which can be assessed by sonography-based morphometry [4].

It remains debatable whether catecholamines influenced the findings in the present study, since no controls were examined [5].

In summary, WBV, if applicable in conjunction with a vibrating dumbbell, appears safe and feasible in early rehabilitation. Potential beneficial long-term effects remain to be shown.

\footnotetext{
* Correspondence: alter@uni-marburg.de; koczulla@med.uni-marburg.de ${ }^{1}$ Department of Medicine, Pulmonary and Critical Care Medicine, University Medical Center Giessen and Marburg, Philipps University Marburg, Baldingerstrasse, 35033 Marburg, Germany
}

Abbreviations

WBV: Whole-body vibration

\section{Acknowledgements}

None.

\section{Funding}

Not applicable.

\section{Availability of data and materials Not applicable.}

\section{Authors' contributions}

All authors were involved in the intellectual content, interpretation, and in writing the manuscript.

\section{Competing interests}

The authors declare that they have no competing interests.

\section{Consent for publication}

All authors agree to publish this manuscript in the category Letter-to-the-Editor in Critical Care.

\section{Ethics approval and consent to participate} Not applicable.

\section{Publisher's Note}

Springer Nature remains neutral with regard to jurisdictional claims in published maps and institutional affiliations.

\section{Author details \\ ${ }^{1}$ Department of Medicine, Pulmonary and Critical Care Medicine, University Medical Center Giessen and Marburg, Philipps University Marburg, Baldingerstrasse, 35033 Marburg, Germany. ${ }^{2}$ Outpatient Pulmonary Rehabilitation, Remigius Hospital, 51379 Leverkusen-Opladen; Medical School University of Witten/Herdecke, 58448 Witten, Germany. ${ }^{3}$ Department of Respiratory Medicine and Pulmonary Rehabilitation, Schoen Klinik Berchtesgadener Land, 83471 Schoenau am Koenigssee; Philipps University Marburg, Baldingerstrasse, 35033 Marburg, Germany.}

Published online: 13 April 2017

\section{References}

1. Wollersheim T, Haas K, Wolf S, Mai K, Spies C, Steinhagen-Thiessen E, Wernecke KD, Spranger J, Weber-Carstens S. Whole-body vibration to prevent intensive care unit-acquired weakness: safety, feasibility, and metabolic response. Crit Care. 2017:21(1):9.

2. Boeselt T, Nell C, Kehr K, Holland A, Dresel M, Greulich T, Tackenberg B, Kenn K, Boeder J, Klapdor B, et al. Whole-body vibration therapy in intensive care patients: a feasibility and safety study. J Rehabil Med. 2016;48(3):316-21.

3. Jarosch I, Gehlert S, Jacko D, Koczulla RA, Wencker M, Welte T, Bloch W, Janciauskiene S, Kenn K. Different training-induced skeletal muscle 
adaptations in COPD patients with and without alpha-1 antitrypsin deficiency. Respiration. 2016;92(5):339-47.

4. Jiménez Siebert M, Boeselt T, Greulich T, Alter P, Herth F, Kahn N, Bornitz F, Vogelmeier C, Nell C, Hummler S et al. Effects of a 6 week whole-body vibration training (WBVT) in stable COPD patients: a randomized clinical trial. Eur Respir J. 2016;48(suppl 60). doi: 10.1183/13993003.congress-2016.PA2216.

5. Di Loreto C, Ranchelli A, Lucidi P, Murdolo G, Parlanti N, De Cicco A,

Tsarpela O, Annino G, Bosco C, Santeusanio F, et al. Effects of whole-body vibration exercise on the endocrine system of healthy men. J Endocrinol Invest. 2004;27(4):323-7. 